\section{Digital reference services: a snapshot of the current practices in Scottish libraries}

\author{
Gobinda Chowdhury and \\ Simone Margariti
}

\section{The authors}

Gobinda Chowdhury and Simone Margariti are based at the Graduate School of Informatics, Department of Computer and Information Sciences, University of Strathclyde, Glasgow, UK.

\section{Keywords}

Libraries, Information services, Information retrieval, Reference services, Digital libraries, Scotland

\section{Abstract}

Discusses the current practices followed by some major libraries in Scotland for providing digital reference services (DRS). Refers to the DRSs provided by three academic libraries, namely Glasgow University Library, the University of Strathclyde Library, and Glasgow Caledonian University Library, and two other premier libraries in Scotland, the Mitchell Library in Glasgow and the National Library of Scotland in Edinburgh. Concludes that digital reference services are effective forms of service delivery in Scotland's academic, national and public libraries, but that their full potential has not yet been exploited. E-mail is the major technology used in providing digital reference, although plans are under way to use more sophisticated Internet technologies. Notes that the majority of enquiries handled by the libraries are relatively low-level rather than concerning specific knowledge domains, and training the users to extract information from the best digital resources still remains a challenge.

\section{Electronic access}

The Emerald Research Register for this journal is available at www.emeraldinsight.com/researchregister

The current issue and full text archive of this journal is available at

www.emeraldinsight.com/0024-2535.htm

\section{Introduction}

Recent changes in computer and communication technologies, especially the introduction and development of the Internet and its associated $\mathrm{Web}$ technologies in the course of the past decade have significantly influenced both the way libraries provide information services to their patrons and the way patrons choose to access information. For example, a large number of Web-based reference services have appeared over the past few years. While dotcom companies provide most of these services, some libraries and library consortia have also introduced Web-based reference and information services. Such services are termed "virtual" or "digital" reference services. Libraries in the USA have spearheaded digital reference services (DRS), and those in other countries are following suit.

This paper discusses the current practices followed by some major libraries in Scotland for providing DRS. We looked at the DRS provided by three academic libraries, namely Glasgow University Library (GUL), the University of Strathclyde Library (USL), and Glasgow Caledonian University Library (GCL). Furthermore, we review the services offered by two other premier libraries in Scotland, namely the Mitchell Library in Glasgow and the National Library of Scotland in Edinburgh. This study took place towards the later part of 2002 .

\section{Digital reference service: current practices}

Libraries and librarians are no longer the sole providers of reference and information services. Arms (2000) forecasts the likelihood of "brute force computing" leading to the creation of fully automated libraries that can substitute IT for staffing in the performance of tasks that at present require human intellectual ability such as provision of reference services. He argues that computers have massive power that can

Received 22 August 2003

Reviewed 8 September 2003.

Revised 23 September 2003.

Accepted 20 October 2003. 
Digital reference services: the current practices in Scottish libraries

Gobinda Chowdhury and Simone Margariti

outperform humans in some tasks that require speed and accuracy. At the same time he notes that machines "lack the power not of being inclusive, but selective". This means that machines cannot employ judgement, an important element of any reference and information service. Rudner (2000) suggests that patrons have become more independent in their information seeking attitudes, but the quality of their findings is poor due to their inability to select the best information sources. In a recent conference well-known experts discussed the current state of DRS and areas that would be useful for further exploration. Turender (2002) discusses some of these issues, including the essential infrastructure needed to provide advanced reference services such as "live librarians", the cost implications, the technologies that are available, and the need to identify the audience.

Janes (2002) argued that libraries have been providing DRS for a few years and they should move on from experimenting to defining new services. Technologies that can support "live" digital reference can be divided into three categories:

(1) chat software;

(2) remote control software (RCS); and

(3) Web contact centre software.

The different technologies can offer different benefits such as low cost (chat $\mathrm{S} / \mathrm{W}$ ), ability to control the patron's browser and authentication (RCS), and features designed especially for digital reference such as question queuing, scripted messages and session transcripts, as is the case with Web contact software, such as MCLS's (Metropolitan Cooperative Library System), and 24/7 Reference (http:// www.247ref.org/). Disadvantages include the high cost to obtain some of these technologies, platform limitations, and impact on bandwidth and consequently on service time.

The issues described above are among the most discussed topics in digital reference today but there has not been much empirical research in the area so far. While evaluating DRS, one should look at the following major points (Lankes et al., 2000):

- $\quad$ services linked to library's main Web page;

- submission methods to ask queries;

- stated policies;

$\frac{\text { Library Review }}{\text { Volume } 53 \cdot \text { Number } 1 \cdot 2004 \cdot 50-60}$

- technological barriers; and

- presence of FAQs in library Web pages.

Wasik (1999) describes the following six-step process that organisations can follow to offer a successful digital reference service. These can be briefly described as:

(1) Informing. Conduct preliminary research in their area of expertise and in the existing services within their area.

(2) Planning. Develop procedures, methods and policies that reflect the overall organisational goals.

(3) Training. Prepare their staff accordingly with a special training plan.

(4) Prototyping. Pilot-test the service before it is launched to discover problems.

(5) Contributing. Ensure publicity and resource development to support the service.

(6) Evaluating. Ensure regular evaluation of the service to provide information in areas that the service can be improved.

McClennen and Memmott (2003) suggest a model that is based on a set of specified roles for information professionals. They recommend that advanced DRS might employ different information professionals for each of four roles, which are:

(1) "filterer";

(2) "answerer";

(3) "administrator"; and

(4) "coordinator".

The role of the "filterer" can be particularly useful since he/she can take repeated and trivial questions out of the way, and hence let the "answerers" concentrate on questions that require intellectual effort to answer. The "administrator" ensures the smooth running of the service, can add answers to FAQs, create user accounts and perform other technical tasks. Finally, the "coordinator" is dedicated to defining and implementing policies and procedures with a view to taking initiatives for the improvement of the service.

\section{Methodology}

Library Web pages usually provide access to the digital services under consideration. Hence, we visited the Web pages of the selected libraries in 
Digital reference services: the current practices in Scottish libraries Gobinda Chowdhury and Simone Margarit

order to, first, record the services available, second, note how the services are offered and third, view the guidelines for service provision / policy. We looked for certain elements in the libraries' pages such as presence of FAQs, a clear contact interface for "enquiries", online catalogues, and links for material available over the network.

Furthermore, we visited the libraries based in Glasgow and conducted interviews with members of staff to discuss the current state of, and problems associated with, running DRS. A list of discussion topics was selected as a guide to provide some direction for the interviews. The discussions were not confined to close ended questions and the interviewees were encouraged to discuss anything that they felt important.

\section{Modes of remote access to services}

University library resources and reference services can be accessed through each university library's Web site. Alternatively, visitors have the choice of using the telephone numbers provided to call the library and place an enquiry. Table I summarises the services available online for the libraries of study.

\section{Electronic enquiry services}

The central element of any digital reference service is the answering of patrons' queries. The interface should allow users to place queries electronically (usually through a Web form), often via a "Contact us" link in the main menu. In all academic library services listed above there are easy-to-find links for submitting general enquiries and for contacting a librarian. Patrons can also find telephone numbers for the enquiry desks,

$\frac{\text { Library Review }}{\text { Volume } 53 \cdot \text { Number } 1 \cdot 2004 \cdot 50-60}$

and telephone numbers for subject librarians as well. According to their Web pages, academic libraries in Glasgow are committed to answering queries within at least three working days, and the actual turnaround time is for the most part much faster. As for the graphic design and user interface for the enquiry service, these vary from library to library.

GUL provides a direct link for posting queries electronically, found in the library's home page. This link connects to an "enquiry service" divided into a "general enquiries desk" and "Ask a Librarian" (Question Point). There is also a list of "subject librarians" that describes areas of specialization for each one of them. Users can also contact them directly by submitting a query through a Web form.

GCL offers a similar enquiry service. On the main library page, a link points to the "electronic enquiry desk" where users can browse through a list of FAQs before submitting their query using a Web form. If library staff cannot answer, they can refer the query to a member of the "academic liaison" team. They are responsible for identifying and meeting the information needs of students, academics and researchers in the topics of business, science, law, computing, health sciences and social sciences. Furthermore, they can offer on-campus advice and training in the effective use of library resources.

The Andersonian Library, the main library in the USL system, also accepts general enquiries from users, doing so through a single interface where users post their question to the library's e-mail box. There is also a special e-mail box for theses requests only. The Law School and Faculty of Education libraries receive enquiries in separate e-mail boxes. The paper by Davis and Scholfield (2003) in this issue provides further details.

Table I Electronic library services provided by the selected libraries

\begin{tabular}{lllllll}
\hline Library & $\begin{array}{l}\text { General electronicl } \\
\text { remote enquiry service }\end{array}$ & $\begin{array}{l}\text { Catalogue } \\
\text { on Web }\end{array}$ & $\begin{array}{l}\text { Dedicated } \\
\text { Web site }\end{array}$ & $\begin{array}{l}\text { FAQs } \\
\text { page }\end{array}$ & $\begin{array}{l}\text { Collaboration } \\
\text { for answering queries }\end{array}$ & Resources remotely available \\
\hline Mitchell & Yes (by phone) & No & No & No & Yes & Fewer than academic libraries \\
NLS & Yes & Yes & Yes & No & Yes & Fewer than academic libraries \\
USL & Yes & Yes & Yes & Yes & Yes & Yes \\
GUL & Yes & Yes & Yes & Yes & Yes & Yes \\
GCL & Yes & Yes & Yes & Yes & Yes & Yes \\
\hline
\end{tabular}


Digital reference services: the current practices in Scottish libraries

Gobinda Chowdhury and Simone Margariti

The layout of the Web site (http:// www.glasgowlibraries.org/) that hosts the Mitchell's library pages is quite different from the university library Web pages. There is a general telephone number specifically for the Mitchell Library that is open to the public for reference enquiries (http://www.

glasgowlibraries.org/contacts.htm). In addition to this, patrons can use the specific e-mail addresses given to "library sections" and post queries regarding the archives, special collections, research and study collections for arts and sciences, or business services (including government publications and law) by using the corresponding e-mail addresses (there are more specialist links than these, which are merely a sample). Since there is no general enquiry Web form or e-mail address, if the patron does not want to use the telephone, they would have to look through the options and decide which library section is most likely to handle their query.

The general enquiry service offered digitally by the National Library of Scotland provides the user with an online enquiry form. This form also provides useful information on (for example) response targets for the enquirer.

Additional information is also required, such as the reason for the research, how the information will be used, and what sources the patron has consulted already. The library answers the query or redirects it to a participating member of the Question Point "Ask a Librarian" collaboration project. The users receive an answer in their own e-mail box, though the service provides the user with a specific password to enable them to check the "questions and answers page" to track the progress of their query. Answers that could not be delivered are stored there. Additionally, it is worth noting that, besides this form-based enquiry interface, the NLS also offers a variety of standard e-mail enquiry addresses as well, all of which provide a number of alternative routes by which queries can be answered.

\section{Summary}

Generally, there are similarities in the way digital referenced services are provided by Scottish libraries. Libraries answer queries by e-mail or telephone, suggest useful material and instruct the patron on how to obtain further information by using appropriate links or suggesting items available from the library. As mentioned above, some libraries participate in collaborative projects, so they receive queries not only through their enquiry desk (electronic or traditional), but also through services such as "Ask a Librarian". Academic libraries allow their users to search through their catalogues and other electronic resources, such as a wide selection of commercially available electronic journals, databases, online references sources, and the like.

For public and national libraries the situation is frequently different in important regards since networked access to commercial datasets is more problematic. More often the patron may have to visit the library to get access to such online electronic resources, and may then find a reduced number of electronic services available to them by comparison with the academic digital resource environment. However, when the patron visits the public library, staff can then give instruction on how to search and use these digital resources on the library premises. The visit to the library is an opportunity for instructional interaction with skilled library staff.

\section{Comparison with a DRS overseas}

In order to have some basis for comparison, we reviewed the digital service provided by an academic library in Australia, a country that has a longer tradition in distance learning. The University of Technology in Sydney (UTS), together with Strathclyde University, is piloting the provision of DRS around the clock. We viewed the library Web pages (http:// www.lib.uts.edu.au) to see whether the digital reference service UTS offers differed from what is offered by Scottish academic libraries.

UTS has similar electronic resources, such as electronic journals, databases, online catalogues, links to selected Web resources and reference collections (dictionaries, encyclopedias, statistics, directories). Another point of similarity is that e-books are accessible through the library Web page.

However, a point of contrast was that, at the time of writing, UTS had recently introduced a pilot online real-time reference service, called 
Digital reference services: the current practices in Scottish libraries

Gobinda Chowdhury and Simone Margariti

"Alive" that is primarily addressed to UTS students and staff. Patrons can chat with a librarian about their information needs in "real time". The service gives the ability to the librarian to accompany the user when browsing through electronic resources. The librarian does not only offer advice and answer to queries, but they can also train the user online on how to use electronic resources, search the catalogue and so forth.

The service is only available at certain times of day. When it is not available users can use the normal Ask-a-Question service, submitting their query via a Web mail form and receiving an answer by e-mail the next day. Library members can use Web forms to make suggestions to the library and request material they would like the library to acquire. UTS teaching staff can also use an electronic request form to ask the library to digitise material in order to support their online courses. Digitised copies are stored in a server that ensures record keeping complies with copyright issues.

Another digital service that the UTS library has added is "SuperSearch", an information gateway for UTS students and staff.

SuperSearch allows the user to search simultaneously (on and off-campus) across library catalogues and databases. Link technology allows the user to access full text resources and request documents from the user's search results. Users can set up their own profile and create a searchable list of resources tailored to their specific needs, save their searches and view past searches. Again, more information about the UTS service are provided in the paper by Davis and Scholfield (2003) in this issue. These details show that UTS, in common with other Australian and North American libraries, may be regarded as providing a level of digital service that could serve as a benchmark against which services elsewhere can be measured.

\section{General reference material and Web links}

Moving away from real-time "chat"-based DRS, when we compare digital resources, Scottish libraries do provide a comparable mix of subscription and freely available general Web sites. More specifically, USL for example
Library Review

Volume $53 \cdot$ Number $1 \cdot 2004 \cdot 50-60$

provides a set of links (under the heading "Reference Shelf") to quality-controlled sites on the Web. One can find links on resources for converting currencies and measurement units; travel-related information; links to common reference tools such as maps, dictionaries, directories and online encyclopedias, etc.; links to educational institutions such as schools, colleges and universities; links to international organizations including the UN and EU.

The GUL Web site and OPAC provide links to common reference sources ranging from telephone directories, online encyclopedias and dictionaries through material on countries, education, arts, publishing and travelling. GUL also provides access to a wide range of general reference sources that includes directories, encyclopedias, maps, dictionaries, news sources and so on. The NLS provides access to, among many other rich resources, a number of map and image collections. It also provides several links to useful information about Scotland, history, the library world and other links on the World Wide Web for sciences and arts.

\section{FAQs}

FAQs in library pages can have a beneficial impact on the traffic for the enquiry desk clearly laid out FAQs can reduce the amount of repetitive or straightforward operational questions. However, for the Mitchell Library and the National Library of Scotland we did not find any pages that contained frequently asked questions. By contrast, UTS and all the three Scottish academic libraries have FAQ pages.

\section{Resources available only in the library premises}

In the Mitchell Library, collections of CD-ROMs related to library

"sections"(subjects) are available on each floor of the library. Users can use electronic resources covering statistics, marketing reports and products, British Standards, patents, Scottish history links, Scottish drama and fiction. But to do so, they have to visit the premises for certain resources and (in some 
Digital reference services: the current practices in Scottish libraries

Gobinda Chowdhury and Simone Margariti

cases), ask a librarian to do the search for them, since only members of staff have access to a number of online services.

Generally, only fewer online services are available in the public domain for the general user of a public library. This is understandable, since it is very expensive to subscribe to networked services such as online journals, when the number of users is as large as that served by a major metropolitan public library. Some steps can be taken to improve that, such as adding links to sources that are available on the Web for free - for example free e-journals, public domain databases, generally available reference sources, links to access other libraries' OPACS and services and the like. The success of the Mitchell Library in this area is discussed below.

The NLS also has a certain number of resources (databases and CD-ROMs) available only through the library's workstations. But others are also available over the network (see (http:www.nls.uk/catalogues/resources/ index.html). These resources include bibliographic databases and details of publications held in Scottish libraries. Remote users can go to the NLS Web site and find the Bibliography of Scottish Literature in Translation (BOSLIT), Bibliography of Scottish Language (BOSLAN), a Union Catalogue of Art Books in Scotland (UCABLIS), US and Canadian newspaper holdings in Scottish libraries, the Scottish Book Trade Index (SBTI), and Scottish books from 1505-1640 (ALDIS), among others. These are powerful tools with which to answer digital reference enquiries which relate to the NLS's rich Scottish information resources.

Clearly, one answer to the difficulties of sharing commercially produced digital resources with the wider public is to create resources which are free of these constraints. The NLS is making good use of such public domain resources with a strong Scottish identity, and there are a number of other Scottish initiatives which are developing similar public domain resources.

\section{Attempts to promote digital reference and digital resources in Scotland}

Because DRS need digital reference materials to support the online reference interview, it is worth noting some of the projects that aim to optimise such digital resources in Scotland at the present time. The NLS is involved with many of these, and aims to support the co-ordination of digital reference strategy across Scotland through a number of schemes. Similarly, the Scottish Confederation of Research and Academic Libraries, SCURL (http://scurl.ac.uk/) is an association that is committed to projects aiming to bring as many resources as possible online, which will in time facilitate more effective reference services. The following initiatives are significant.

CAIRNS (http://cairns.lib.gla.ac.uk) promotes an academic information retrieval network for Scotland. CAIRNS investigates cataloguing/indexing strategies along with integration of local and central server-based services across libraries. Several Scottish universities are consortium members for CAIRNS with the Universities of Glasgow and Strathclyde being the primary leaders.

The SLAINTE Web site (http:// www.slainte.org.uk/) gives Web-based access to information related to librarianship and information management in Scotland as well as providing a sophisticated search engine that covers a wide variety of resources. The SALSER project (http://edina.ac.uk/salser/) provides a union catalogue of Scottish serials, which enables patrons to discover which journal titles are held in Scottish academic and municipal research libraries and also provides a connection to participating libraries' OPACs. The SAPIENS project, (http://sapiens.cdlr. strath.ac.uk/) which is run by the University of Strathclyde, examines the case for a centralised electronic journal service in Scotland while also providing demonstrator models.

The above plans represent some of the main strands of digital library innovation in contemporary Scottish Universities. Alongside these, one should note that the Mitchell Library is currently developing two digitisation projects that provide online access to searchable databases in Glasgow City libraries. The projects are the "Virtual Mitchell" project (http://www.mitchelllibrary.org/vm) and the "Sir Thomas Lipton" project

(http://www.libarch.glasgow.gov.uk/stll.html). Both databases contain digitised images from Scotland. 
Digital reference services: the current practices in Scottish libraries Gobinda Chowdhury and Simone Margarit

\section{Practice and problems in reference services}

During the interviews with library staff our main aim was to understand the problems librarians face and to discuss initiatives or directions for potential future developments. We investigated how DRS function within established in-house reference services, how librarians respond to patrons' queries electronically, how the work load is handled, what software libraries use and what improvements they would like to see in the provision of service in a digital environment.

\section{Reference in practice}

Staff in libraries explained how the traditional enquiry desks operate on a daily basis. The enquiry desk in the Andersonian Library, University of Strathclyde, is sited close to the IT enquiries desk and is staffed by four members of staff who also receive and answer enquiries via e-mail. Some of these library staff are also responsible for maintaining the library's Web pages. Currently, staff have no special management software to assist with tracking or storing answers to queries, or to enable them to save material for future reference. Some librarians keep certain answers in their personal computer files, though these are not shared. There are separate enquiry services in the education faculty and law libraries, the latter attracting a notably large amount of enquiries for a single department service.

The situation of the enquiry desks is similar between Glasgow and Strathclyde university libraries. In GUL most enquiries are answered on the spot. A few of the more detailed telephone enquiries are recorded on enquiry sheets and filed for future reference. Subject librarians answer queries that relate to their areas of expertise as they are passed to them from general enquiries. Unlike in GUL, in the Andersonian Library, subject librarians work in offices close to the book and journal stock in their subject area on the different floors of the building. But even so senior library assistants are the first contact point at the enquiry desk, with bulk of the enquiry work handled by senior library assistants at the central desk.

In GUL, the enquiry team deals with traditional face-to-face reference enquiries but also with many enquiries by telephone or e-mail. Queries can be of an in-depth, academic nature or simply about operational procedures. Furthermore, enquiries are received not just from members of the university - it is not unusual to receive a significant flow of enquiries from patrons outside the university. Although staff work on the front desk and answer enquiries on the spot where possible, if necessary (for example if the queries are more subject specific), they are passed to "subject" librarians through an e-mail. There is also a special section in the library that deals specifically with maps and official publications, and some queries may be passed on to this section. Alternatively, patrons may contact this section directly.

In GCL there are three separate enquiry desks, one for general enquiries, one for IT enquiries and one for IT assistance for the university's "Learning Café". If staff cannot answer the query they refer it to an "academic liaison" staff member who specialises in the specific area. A broad spectrum of staff (library assistants, subject librarians and administrators) participate in answering reference enquiries. In GCL, staff can use the library's intranet to save frequently asked questions for future reference. The IT enquiry desk also uses a type of management software (RMS) to handle queries but expansion and integration of this service with the rest of the enquiry desks is a possible future development. The university recently introduced the "Learning Café" to encourage use of the digital resources available over the university's academic network in a relaxed atmosphere. The relevant enquiry-help desk is situated in the same premises with the Café.

The in-house enquiry service in the Mitchell Library is configured differently from the centralised services of academic libraries. Every floor in the library has its own team consisting of two or three members of staff who are responsible for answering queries. The library is heavily used by the general public, and a majority of the questions are asked on the spot or through the telephone. If a staff member cannot answer a question they can call or e-mail another member of staff for assistance.

Turning to the networked or distance reference services at the Mitchell Library, these interact with, support, and are supported by, 
Digital reference services: the current practices in Scottish libraries

Gobinda Chowdhury and Simone Margarit

the library's networked information resources. As noted above, there are difficulties in providing remote access to digital resources for public library users, but the Mitchell Library has made some significant achievements in this area. For example, as part of the Mitchell Library's commitment to community information, it supports and works with the Sandyford Clinic (http://www.glasgowlibraries. org/sandyford.htm), an initiative that promotes a wide range of sexual health and reproductive health services via a library and information service based near to the Mitchell Library . The Mitchell Library's catalogue is available from computers on the premises of the Sandyford Clinic, whose reading material is in turn included in the Mitchell Library catalogue in an effort to use the network to promote the local community's access to these information resources. The next step is to include the materials held in Glasgow Royal Infirmary to the library's main catalogue.

More broadly, some of the resources on the Mitchell Library's Web pages (available at (http://www.glasgowlibraries.org/ onlineresources.htm) can be used remotely.

All of these are good examples of the sort of rich digital resources that can support a digital reference service aimed at community information needs, rather than, for example, the purely academic information needs of a clearly defined academic user population.

\section{Reference service problems}

\section{Query management software}

Many librarians pointed out that DRS in academic libraries will typically process a large volume of enquiries, but they also say that the electronic enquiry desk lacks enquiry management software which could help manage such a large volume of enquiries. Library staff suggested that the use of software that could automatically distinguish between unique or demanding reference questions and repetitive, simple queries might solve a great deal of problems. This would help librarians concentrate on answering queries that require more research. However, it is obvious that no such ideal software tool currently exists.

Because librarians do not have software to record the volume of DRS enquiries, these are for the most part manually recorded on paper
Library Review

Volume $53 \cdot$ Number $1 \cdot 2004 \cdot 50-60$

instead. An alternative is to add "original" patron questions to FAQs pages, a time-consuming activity. Original texts need manual editing before doing so, since patrons tend to include personal information that has to be removed. There is clearly a potential role for time-saving software to be introduced to address these problems.

Cost implications: acquisition of digital material to support DRS

In any academic library, the most heavily used items are available in the short-loan collection in multiple copies. However, this is not always enough to satisfy the need for certain high demand titles and multiple networked access to electronic text seems to offer a way of addressing the need for multiple access to highly popular material. DRS similarly require an ample supply of such digital material to form the basis of virtual interactions with users.

If electronic books seem to provide a good solution for such problems, it is worth querying why provision of electronic reference book material has not yet expanded to levels commensurate with the hard copy monograph provision in many libraries. An issue of prime importance is economics: the costs of e-book provision must be adequately dealt with if the medium is to expand.

Digital provision of the entire text of many high quality student or reference books is expensive, not least because many such e-books are made available on a subscription basis as part of large "compulsory purchase" multi-title services. These replicate many of the cost disadvantages of the worst type of all-in-one, subscription-only e-journal service, whose enormous market dominance, inflexibility, complex pricing structures and spiralling expense have earned much disapproval from librarians world-wide.

In contrast to these all-encompassing services (which effectively force libraries to buy little used material alongside heavily-used material), there may be some merit in concentrating more on e-book excerpts, such as heavily used chapters from text books which could be made available on demand in electronic format. HERON (http://www.heron.ac.uk/), currently a service managed by Ingenta, helps with the digitisation process and the delivery of book 
Digital reference services: the current practices in Scottish libraries

Gobinda Chowdhury and Simone Margariti

extracts, and negotiates issues regarding copyright clearance. HERON has recently increased its electronically available titles to two million and encourages more publishers to become members of its electronic community. The idea behind it is that lecturers can request chapters to be digitised and the cost depends on the number of pages requested and the number of students that could benefit from the service. The service comes at a reasonable cost in the short run, since access to full electronic books available straight from the publisher would come at a higher price. This scheme is a promising way to provide the academic community with more digital documents, since it allows consumers to choose which titles or excerpts of titles they wish to purchase. This contrasts strongly with other purely commercial deals which demand that entire portfolios of titles are purchased, even if only a handful within a portfolio are genuinely needed.

However, at the time of writing the availability (or rather lack of availability) of digital reference material is a limiting factor on the spread of digital reference. Issues such as the models of pricing for e-book services are one of a number of factors which need to be addressed if this problem is to be solved.

\section{Plans for the future}

Plans are under consideration at Strathclyde, GUL and the Mitchell libraries for providing live electronic chat services with librarians. Specifically, the Mitchell Library is preparing for the "live" chat service in the near future - at present, although the Mitchell Library participates in the Ask-a-Librarian consortium, there is no direct link in its library pages pointing to the service. Future enhancements to its digital services include plans for its catalogue to be available through the library's Web pages.

Plans for public libraries such as the Mitchell Library must recognise that such libraries are serving a different audience from academic libraries: the priority is that the general public rather than students are the main service users. Because of this, the library's focus has changed from being student-orientated to one more widely dedicated to the information needs of the general public - thus, the library has moved
Library Review

Volume $53 \cdot$ Number $1 \cdot 2004 \cdot 50-60$

away from the purchase of text books and does not attempt to replicate the computer technology that students have access to on campus. It is still planned to add more computers in its premises soon, but to provide visitors (only 40 per cent of whom come from Glasgow) better access to the Internet and online digital resources.

Thus, it is fair to say that academic, national and public libraries can and do provide a good range of electronic publications, databases and general reference materials. However, acquiring digital material becomes increasingly expensive as subscription fees accumulate. While subscription models rather than one-off purchase models of acquisition dominate electronic service provision, libraries will have a complicated task to manage and maintain the long run costs of digital resources. Without such resources the function of DRS will be severely undermined.

\section{Conclusion}

Overall, it is certainly fair to say that a particular strength of the DRS in the libraries surveyed is the high quality Web pages they offer, which are consistent in quality and are user-friendly, providing an accurate list of all the services offered by each library. Many students in fact report to library staff that they use the library pages more than the library premises to search for information.

However, it is important to note some disadvantages in the way these pages are used for reference work. A great majority of reference enquiries directed to the contact e-mail boxes in these pages are "mechanical" queries on how to use IT resources rather than specific higher level enquiries about subjects and knowledge domains in the best tradition of face-to-face reference work. Again, the synchronous nature of traditional face-to-face reference work is lacking, limiting the potential for genuinely instructional interaction with staff and the promotion of information literate use of digital resources. More simply, e-mailing a query and receiving an answer the next day might not give a fast enough turnaround time. These asynchronous e-mail tools may require the enquirer to start up their information seeking 
Digital reference services: the current practices in Scottish libraries

Gobinda Chowdhury and Simone Margariti

session all over again, since the thread of the interaction has been lost.

When discussing digital reference in both academic and public libraries we identified a common weakness: more often than not, all kinds of enquires, irrespective of their nature, come to the same mail box. Librarians take turns in answering a great deal of relatively low level e-mails regarding non-study related issues. Filtering is a problem. But beyond this, the higher goal of training the users to extract information from the best digital resources still remains a challenge. Libraries are therefore considering the provision of "chat" services with a specific goal in mind, as a means of upgrading the level of their interaction with their users. Real-time electronic reference, along the line of the Australian model examined above, may be a tool by which the librarian can train the patron to use resources and assist in the intellectual part of the information seeking process by facilitating more intense coaching sessions with much more iterative interaction. E-mail cannot do this.

Of course, the filtering of enquiries is a problem for traditional help desk services in libraries. Many academic libraries now have IT desks alongside library reference desks, but apparently many people prefer just to ask at the first "enquiries" desk they come to. The goal of any DRS should be to offer an improved process, with better filtering and thus better direction of tasks to librarians.

As McClennen and Memmott (2003) discuss in their consensus model about roles in DRS, adjustments in the flow of the service can make it work more efficiently. From this study we noted that academic libraries have a strong sense of the need for strategic direction in the management of digital reference and staff are very much aware of DRS as a positive tool for improving services to users. In fact a few straightforward alterations in operational procedures can significantly improve the service. For example, before using the Web form to send a query, a message delivered by a link just above the Web form can prompt a patron to browse through the list of FAQs.

Following on from this, where recourse to a list of FAQs does not satisfy the user, an administrator, possibly using reference
Library Review

Volume $53 \cdot$ Number $1 \cdot 2004 \cdot 50-60$

management software, can then classify the enquiries according to their topic.

Procedural enquiries can be answered by an appropriate person, while the remaining "in-depth" enquiries can be forwarded to specialist librarians. The administrator could also take care of the paperwork, edit and add FAQs and distribute queries to subject librarians.

One other problem that was made clear in the interviews, is that libraries do not at present have a means of keeping entries of enquiries electronically. Consequently, it is harder to generate statistics about service usage. This is a particular problem in public libraries where a lot of queries come through the telephone. The paper forms take time to fill in and are not very efficient in providing a snapshot of the whole enquiry service. However, it is likely that the reference services described in this paper will be developing such features in the near future, as the benefits of such enhancements become firmly established in library practice.

Finally, the problems of public libraries in offering networked digital services (as mentioned above) may have implications for the role of academic libraries. Although students and academics are the primary users of academic libraries, it can be argued that these libraries should also extend digital resource access and any DRS supporting them to the general public. According to this argument, it is unfair that academic institutions (funded from the public purse) hold valuable resources that are not available in public libraries. However, such libraries do not have the power to change such arrangements and must simply operate within the legal restrictions imposed upon them by commercial suppliers. But if present licence agreements set up with commercial dataset suppliers prevent such an extension of access, it is to be hoped that nationally negotiated agreements will move closer to such community access models in the future.

\section{References}

Arms, W.Y. (2000), "Automated digital libraries: how effectively can computers be used for the skilled tasks 
Digital reference services: the current practices in Scottish libraries

Gobinda Chowdhury and Simone Margariti

of professional librarianship?", D-Lib Magazine, Vol. 6 No.7/8, available at: www.dlib.org/dlib/july00/arms/ 07arms.html

Davis, K. and Scholfield, S. (2003), "'Beyond the virtual shore': an Australian digital reference initiative with a global dimension", Library Review, Vol 53 No. 1, pp. 61-5.

Janes, J. (2002), "Digital reference: reference librarians' experiences and attitudes", Journal of the American Society for Information Science and Technology, Vol. 53 No. 7, pp. 549-66.

Lankes, D., Collins, J.W. and Kasowitz, A.S. (Eds) (2000), Digital Reference Service in the New Millennium: Planning, Management, and Evaluation, Neal-Schuman, New York, NY.
Library Review

Volume $53 \cdot$ Number $1 \cdot 2004 \cdot 50-60$

McClennen, M. and Memmot, P. (2003), "Roles in digital reference", Information Technology and Libraries, Vol. 29 No. 3, available at: www.lita.org/ital/ 2003_mcclennan.htm

Rudner, L. (2000), "Who is going to mine digital library resources? And how?", D-Lib Magazine, Vol. 6 No. 5, available at: www.dlib.org/dlib/may00/runder/ 05runder.html

Turender, H. (2002), "Digital reference: trends, techniques and changes", Library Hi Tech News, available at: http://masetto.emeraldinsight.com/v1=9380369/ $\mathrm{cl}=29 / \mathrm{nw}=1 / \mathrm{rpsv} / \mathrm{cw} / \mathrm{mcb} / 07419058 / \mathrm{v} 19$

Wasik, J.M. (1999), "Building and maintaining digital reference services", ERIC Digest, available at: www.ed.gov/databases/ERIC_Digests/ed427794.html 